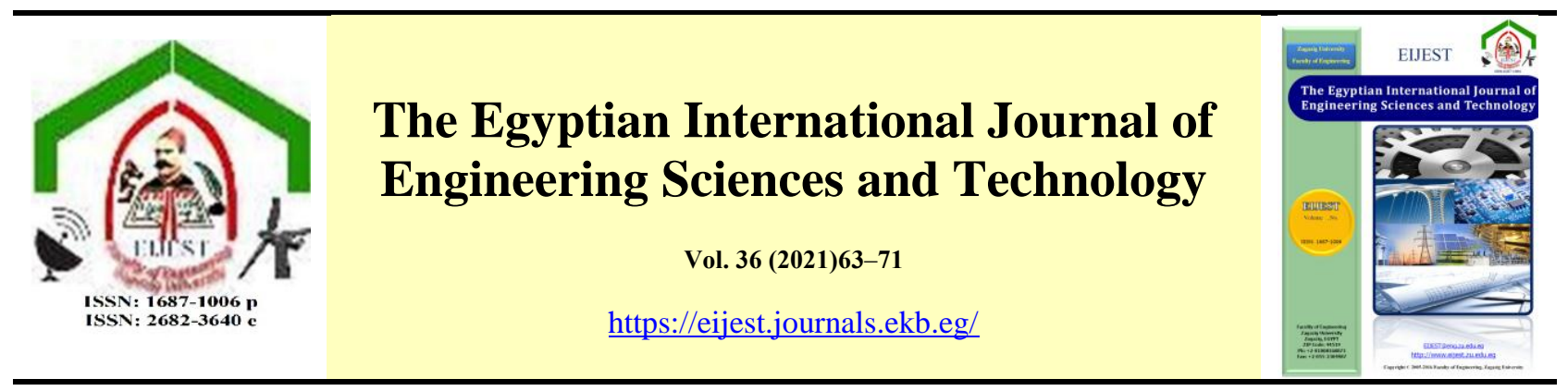

\title{
Mechanical properties and corrosion behavior of sugarcane Bagasse fiber reinforced Low Density Polyethylene composites
}

\author{
Mohamed A. EL-meniawy ${ }^{\mathrm{a}}$, Ayman M. Abdelhaleim ${ }^{\mathrm{b}}$, Asmaa H. Abdelnaby ${ }^{\mathrm{a}}$, Dalia Saber ${ }^{\mathrm{a}, \mathrm{c}}{ }^{\text {* }}$ \\ ${ }^{a}$ Materials Engineering Department, Faculty of engineering, Zagazig University, Zagazig 44519, Egypt \\ ${ }^{b}$ Mechanical Design and Production Engineering Department, Faculty of engineering, Zagazig University, Zagazig 44519, Egypt \\ ${ }^{c}$ Industrial Engineering Department, college of Engineering, Taif University, Saudi Arabia.
}

\begin{tabular}{ll}
\hline A R T I C L E I N F O & A B S T R A C T \\
\cline { 2 - 3 } $\begin{array}{l}\text { Keywords: } \\
\text { biocomposites }\end{array}$ Mechanical properties & $\begin{array}{l}\text { In the recent decade, there has been an increase in global warming, environmental } \\
\text { changes, and other issues. Environmentally friendly products, such as natural } \\
\text { Corrosion }\end{array}$ \\
composite materials, are being developed by researchers and academics to protect \\
life on the planet. The purpose of this research is to see if cellulose and cellulignin \\
fibres obtained from sugarcane bagasse (SCB) waste may be used as reinforcing \\
filler in a thermoplastic polymer matrix. The injection method was used to create \\
the low density polyethylene (LDPE) and sugarcane bagasse (SCB) composites. \\
Fiber loading was set to be varied from 10 to 30 wt\%. To improve interfacial \\
bonding, the fibres were chemically modified using an alkali treatment, and the \\
effects on the fiber/matrix interaction were evaluated using scanning electron \\
micrographs (SEM). Tensile, impact, and hardness were used to determine the \\
mechanical properties and corrosion tests. The findings revealed that sugarcane \\
bagasse fibers, like other natural fibers, strengthen polyethylene. It has been found \\
that the tensile strength and tensile modulus of the treated SCB fibers have been \\
improved significantly by about 13\% and 196\%, respectively, compared to neat \\
LDPE. This was due to the observed enhancement in the interfacial adhesion \\
between the fiber and matrix. The impact resistance and hardness of the composite \\
enhanced by 55.28\% and $26 \%$, respectively, over neat LDPE. According to SEM \\
analysis, the alkali treatment affected the morphology of fibers.
\end{tabular}

\section{INTRODUCTION}

Increased environmental awareness and societal interest have resulted in the widespread usage of environmentally friendly materials for example natural fiber as sugar cane bagasse, bamboo, banana, coir, cotton, flax, hemp, jute, and turmeric. Natural fiber is an environmentally friendly material with superior qualities over plastic. Natural fibers have several advantages over synthetic fibers, including low cost, low density, comparable specific tensile qualities, lower health risk, renewability, recyclability, and biodegradability [1-3]. Natural fiber composites are one of the most appealing replacements for nonbiodegradable glass and carbon fibers in the fabrication of thermosetting and thermoplastic composites[4,5]. Researchers and industries prefer Vegetable fibers with better properties than synthetic fibers because of their wide range of applications in industries such as, fiberboard, cushion, paper, mattress, door, automotive, wall panel, air cleaner, dashboard, and insulation mat manufacturing, food-

\footnotetext{
* Corresponding author. Tel.: +2-01223667942; Fax: +2-055-2304987

E-mail address: daliasaber13@yahoo.com
} 
packaging, as well as construction and transportation[6].

The key to transferring stress from the matrix into the fibers through the interface is interface bonding between the fillers and the matrix. Natural fibers have several advantages, as indicated above. Still, they also have some disadvantages when used in polymer matrix composites, such as high moisture sorption variability in fiber characteristics and a tendency to agglomerate during processing[7-10]. Natural fiber has a high hydrophilic property since it is made up of lignocellulose, which contains numerous hydroxyl groups $(-\mathrm{OH})[11]$. As a result, these fibers are fundamentally incompatible with hydrophobic polymer matrix materials, with poor interfacial adhesion between hydrophilic natural fibers and typical resin matrices being particularly problematic.

The incompatibility may cause problems in the composite processing and material properties[12]. This causes a wetting issue, poor interfacial adhesion, and limited stress transmission between the two interfaces, all of which significantly impact strength growth. [13]. Thus, Numerous chemical treatments of plant fibers could be utilized to circumvent these constraints and increase compatibility with polymer matrices. [14]. One of the approaches that develop the inherent properties of natural reinforcements is the alkali treatment of the natural reinforcements. Alkali treatment is the simplest and most cost-effective method of altering natural fibers. It is a longestablished commercial technology that involves treating the fibers with a sodium hydroxide solution[15-17]. The influence of chemical treatments on the mechanical properties of natural fiberreinforced composites was examined by many researchers. Maryana et al. [18] investigated The chemical composition and structure of sugarcane bagasse after alkaline pretreatment. The properties of sugarcane bagasse before and after pretreatment have been studied. The treatment with $\mathrm{NaOH}$ had the lowest lignin level, according to the findings.

Sugarcane bagasse is abundant and has a softer structure than other types. Its availability as waste from agricultural waste and waste from the sugar mill's production process could reinforce the polymer [18]. Alexandre et al.[19] Examined Polypropylene (PP) and sugarcane bagasse fiber composites with and without alkali treatment. They also looked into the composites' thermal and mechanical properties. After the chemical treatment process, scanning electron microscopy (SEM) demonstrated improvements in the fiber's surface topography. The alkali treatment changed the fiber surface as well as the chemical composition, according to TGA and SEM data. They concluded that the mechanical and thermal properties of the material had improved. Santhanam \& Chandrasekaran [20] attempted to make a composite using bagasse fiber and epoxy resin. Alkali treatment changed the surface of the fibers. They looked at the impact of fiber surface modification on mechanical characteristics, including tensile strength in composites made using milled fibers. The tensile strength of alkali-treated bagasse/epoxy composites was found to be greatly improved. The surface modifications also boosted the fiber-matrix interaction, according to SEM analysis. Mulinari et al. [21] tested Low Density Polyethylene (LDPE) composites reinforced with King Palm fibers for mechanical and thermal properties. Mechanical properties were determined using tensile, flexural, and impact specimens. SEM micrographs of broken surfaces and thermal analyses were used to evaluate the composites. The results showed that the reinforcement reduced the composites' thermal stability but increased their tensile, flexural, and impact strength significantly.

The goal of this research was to investigate the mechanical properties as well as the corrosion behavior of composites made from untreated and treated fibers. Scanning electronic microscopy was used to explore the effects of interfacial morphology and matrix-fiber interaction on the mechanical characteristics of produced composites within the framework (SEM).

\section{MATERIALS AND METHODS}

\subsection{Materials}

The Low Density Polyethylene (LDPE) (SABIC® LDPE HP20023) used as the starting matrix with a melting temperature of $112^{\circ} \mathrm{C}$. Table 1 shows its physical and mechanical properties. The sugarcane bagasse (SCB) used as filler was directly obtained from sugar cane mills after being processed to extract sugar and liquor. 
Table 1. Properties of low density polyethylene (LDPE).

\begin{tabular}{|cc|}
\hline Property & Polyethylene \\
\hline Density $\left(\mathrm{g} / \mathrm{m}^{3}\right)$ & 923 \\
Melt Flow Rate & $20 \mathrm{~g} / 10 \mathrm{~min}$ \\
at $190^{\circ} \mathrm{C}$ and $2.16 \mathrm{~kg}$ & 9 \\
Tensile strength $(\mathrm{MPa})$ & 7 \\
flexural strength & 175 \\
flexural modulus & 150 \\
strain at break & 500 \\
Izod Impact Strength $\left(\mathrm{J} / \mathrm{m}^{2}\right)$ & 45 \\
Hardness Shore D & \\
\hline
\end{tabular}

\subsection{Chemical treatment using sodium hydroxide.}

Bagasse fibers were dried in the sun for one week to eliminate moisture content, then crushed into small pieces using a crusher machine. This fiber was immersed in a 3\% aqueous sodium hydroxide solution for 8 hours at $30^{\circ} \mathrm{C}$ [22], with a liquor ratio of $15: 1(\mathrm{w} / \mathrm{v})$ [23], allowing hemicellulose, lignin, and other fatty components to be removed [24].The fibers were rinsed with water multiple times to eliminate any $\mathrm{NaOH}$ solution that had adhered to their surface. Treating SCB withsoduim hydroxide causes fibrillation, breaks SCB bundles and increase the surface roughness[25]. The fibers were then air-dried for 24 hours at ambient temperature before being oven dried for 24 hours at $80^{\circ} \mathrm{C}[26,27]$ as shown in figure 1.

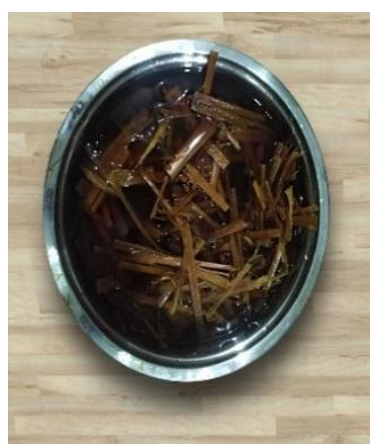

(a)

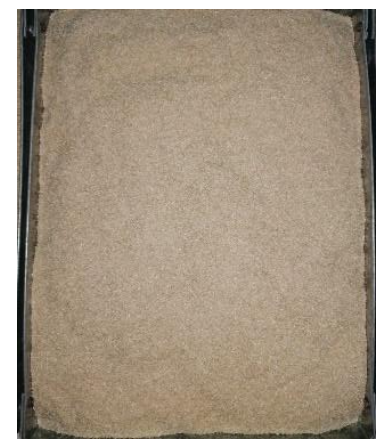

(b)
Figure 1. sugarcan bagasse fibers. (a) SCB soaked in $\mathrm{NaoH}(b)$ treated SCB

\subsection{Fabrication of composite laminates}

Polyethylene pellets were combined with ground SCB fibers. To avoid void generation, both bagasse fiber and LDPE were dried in an air oven before making composite samples. For each weight fraction, the required amount of fiber and matrix was weighed (10wt \%, 20wt \%, and 30wt \%) of untreated and treated cellulose and cellulignin fibres. Sugarcane bagasse fibres were incorporated together with the matrix. The composites were injected directly into a mold with predetermined dimensions after mixing as shown in fig 2 . The five heating zones had processing temperatures of $140,160,170,200$, and $220^{\circ} \mathrm{C}$, respectively. There was a pressure of 100 bar. Tablel 2. listed the composition of the studied formulation. Treating SCB (TSCB) and untreating SCB (UTSCB).

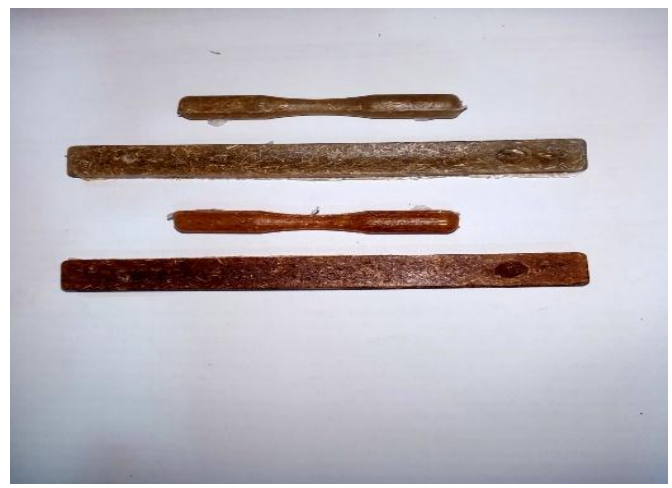

Figure 2. injected specimens.

Table 2 composition of the studied formulation.

\begin{tabular}{|cccc|}
\hline Sample & LDPE (wt $\%)$ & Pre-treatment & $\begin{array}{c}\text { Fiber } \\
\text { content }\end{array}$ \\
\hline Neat LDPE & 100 & - & - \\
& 90 & None & 10 \\
UTSCB & 80 & None & 20 \\
& 70 & None & 30 \\
TSCB & 90 & $\mathrm{NaOH}$ & 10 \\
& 80 & $\mathrm{NaOH}$ & 20 \\
& 70 & $\mathrm{NaOH}$ & 30 \\
\hline
\end{tabular}

\subsection{Mechanical testing}

\subsubsection{Tensile test}

The tensile tests were executed with Jinan Test Machine (WDW $100 \mathrm{KN}$ ) universal testing machine supplied from Jinan Xinluchang (Testing Machine Co., Ltd, Jinan City, Shandong Province, China). Tensile testing was carried out in accordance with (ASTM D638 type V). The test was run at $2 \mathrm{~mm} / \mathrm{min}$ crosshead speed. The average tensile strength value of five samples for each composition was calculated.

\subsubsection{Impact test}

The Izod impact test was used to determine the impact strength and absorbed energy in accordance with ASTM D256. Impact tests were performed on Vnotched specimens using an AVERY Denison impact machine. The pendulum has a $3.8 \mathrm{~m} / \mathrm{s}$ falling velocity and a $15 \mathrm{~J}$ impact energy. The impact strength was determined by dividing the absorbed energy by the sample's original cross-section area. 


\subsubsection{Hardness testing}

The fiber volume fraction and modulus have a significant impact on the hardness of a fiber-reinforced composite[28]. Hardness value determines the plastic material's resistance to being penetrated by the indenter. Hardness was measured by Hardness shore D Tester instrument in accordance with ASTM D 2240. Hardness was measured at eight different random points for each composite sample, the mean value of hardness was calculated.

\subsubsection{Chemical resistance test}

The Corrosion resistance test is usually performed for the primary acids, alkalis, and solvents. The most widely used chemicals in the category of the acid include: concentrated sulfuric acid (10wt $\left.\% \mathrm{H}_{2} \mathrm{So}_{4}\right)$, determined resistance to alkalis is generally examined for the aqueous solution of sodium hydroxide (10wt\% $\mathrm{NaOH}$ )[29]. However, a common solution, sodium chloride $(3.5 \mathrm{wt} \% \mathrm{NaCl})$, was utilized to investigate the chemical resistance of composites against the chemical solution. The materials are weighed and then immersed in chemical reagents for 24 hours in the standard experimental procedure. In most cases, the experiments are carried out at room temperature. The samples are removed, rinsed with distilled water, and dried between filter sheets after a 24-hour interval. After that, the samples were weighed to calculate the percentage of weight gain. The following equation was used to calculate the percentage of weight gain [30,31].

$$
\begin{aligned}
& \% \text { weight gain of the sample }= \\
& \frac{\text { final weight-original weight }}{\text { original weight }} \times 100
\end{aligned}
$$

\subsubsection{Scanning electron microscopy (SEM)}

Scanning electron microscopy (SEM) was used to evaluate fiber dispersion/distribution in the polymer matrix, Using an FEI Quanta 200i instrument to investigate the morphological behavior of the untreated and chemically modified fiber surface and the fractured surfaces of natural composites. Prior to each analysis, the surfaces of natural composite specimens were sputter-coated with gold.

\section{RESULTS AND DISCUSSIONS}

\subsection{Tensile properties}

Figure 3-5 displays the mechanical properties (tensile strength and Young's modulus (modulus of elasticity)) of neat LDPE, untreated and treated sugarcane bagasse composites with various SCB fiber loadings. The tensile strength of the alkali-treated SCB/LDPE composites was higher than that of neat LDPE and the untreated SCB/LDPE composites[32]. On the other hand, Untreated SCB had lower tensile strength than LDPE, which might be attributable to fiber pullout and debonding of the untreated SCB fibers from the LDPE matrix[32,6]. The tensile strength and Young's modulus characteristics were obtained as a result of this interaction. The tensile strength of treated SCB fiber reinforced with LDPE increased from 12.47 to $13.23 \mathrm{MPa}$ for $10 \mathrm{wt} \%$ to $30 \%$, respectively. Generally, a high fiber-loading content develops the composites mechanical properties[24]. The tensile strength and Young's modulus showed a growing trend From 10 wt $\%$ to $30 \mathrm{wt} \%$ fiber loadings. The tensile strength and Young's modulus of $30 \mathrm{wt} \%$ alkali-treated fiber loadings exhibited a considerable increase by $13 \%$ and a 196\%, respectively, over LDPE. In the meantime, the maximum tensile strength was attained at 30wt\% SCB fiber loading in the LDPE matrix. The tensile strength of the $30 \mathrm{wt} \%$ SCB/LDPE composite increased by $13 \%$ compared with LDPE, whereas Young's modulus was $196 \%$ higher than that of LDPE. The failure of tensile specimens is a complete fracture into two parts in the specimen gage length across the cross section as shown in Figure 6. The mechanical strength and Young's modulus were influenced by the morphology of the untreated and treated SCB/LDPE composites. And would be also influenced by defects that occurred during the injection of the SCB/LDPE samples. Tensile strength and Young's modulus of tensile strength are listed in Table 3. the untreated SCB fibers had weak interfacial bonding with the LDPE matrix compared to the treated SCB/LDPE composite[34].

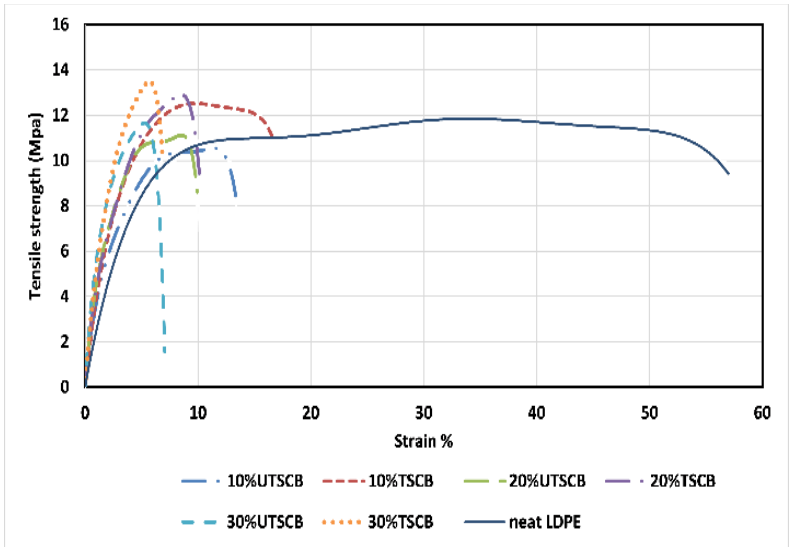

Figure 3. the stress- strain curve of SCB fiberreinforced composites 


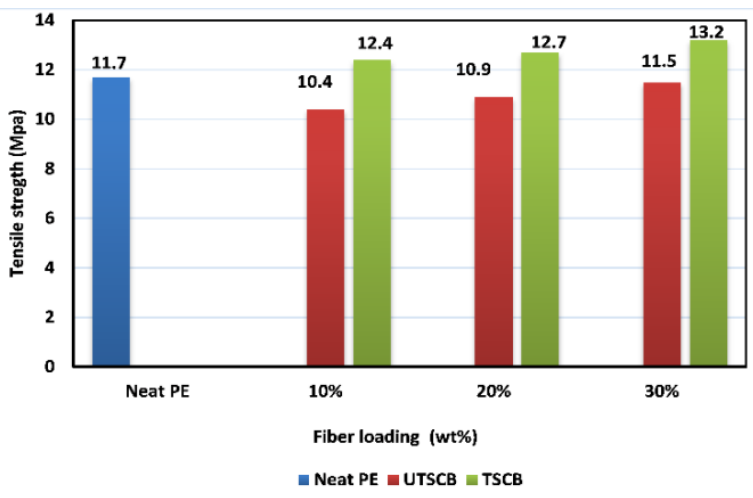

Figure 4.Tensile strength of SCB fiber-reinforced composites.

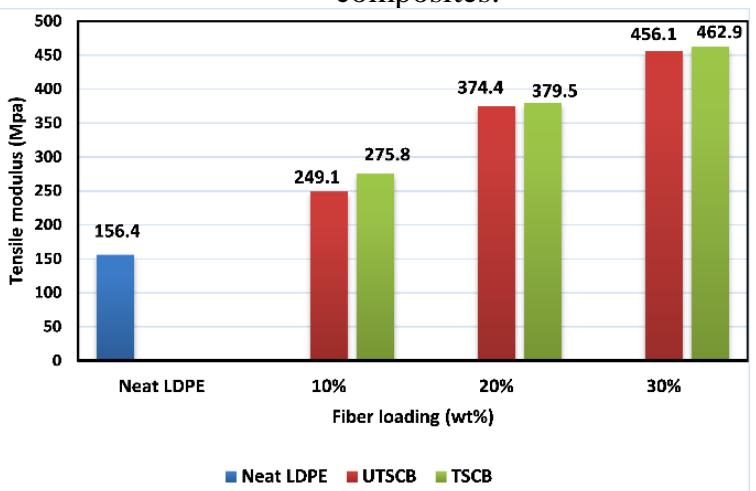

Figure 5. Tensile modulus of SCB fiber-reinforced composites.

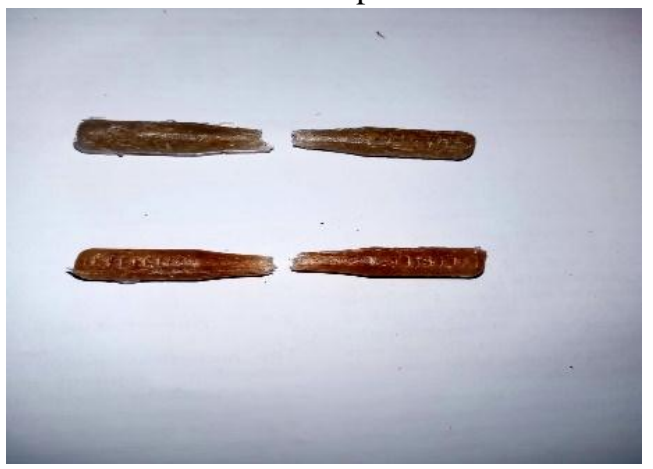

Figure 6. Common failure modes for tensile test specimens

Table 3. tensile strength and modulus of SCB reinforced LDPE.

\begin{tabular}{|ccc|}
\hline sample & $\begin{array}{c}\text { Tensile } \\
\text { strength(Mpa) }\end{array}$ & $\begin{array}{c}\text { Tensile } \\
\text { modulus(Mpa) }\end{array}$ \\
\hline Neat LDPE & 11.71676 & 156.4 \\
10\%UTSCB & 10.43788 & 249.149 \\
20\%UTSCB & 10.94705 & 374.47 \\
30\%UTSCB & 11.513 & 456.15 \\
10\%TSCB & 12.47454 & 275.8 \\
20\%TSCB & 12.72912 & 379.598 \\
30\%TSCB & 13.23829 & 462.91 \\
\hline
\end{tabular}

The treated SCB fibers were embedded in LDPE, whereas the untreated SCB fibers were pulled out. [35]. The interfacial adhesion and flow of LDPE within SCB fibers were primarily responsible for this result. The alkali treatment improved the surface adhesion of the fibers, which is beneficial for greater compatibility between fiber and matrix.

\subsection{Impact properties}

The failure of impact specimens is a complete fracture into two parts in the specimen gage length across the width as shown in Figure 7. The results of the Izod impact test are reported in table 4 and impact strength values disply in Fig.8. The effects of bagasse fibers on the impact strength are examined and discussed in this part. It can be seen that there was an improvement in the impact strength due to the inclusion of bagasse fibers[36]. The strength increased from 64.4 to100 $\mathrm{KJ} / \mathrm{m}^{2}$ for neat LDPE and $30 \mathrm{wt} \%$ treated SCB composite, respectively. From the present observations, it can be concluded that there was an enhancement in the impact strength with increase in the percentage of SCB fiber loading[37]. This is attributed by the higher energy need to be supplied to the fiber to pull out at higher filler content and good interfial bonding between the fiber and the matrix [38].

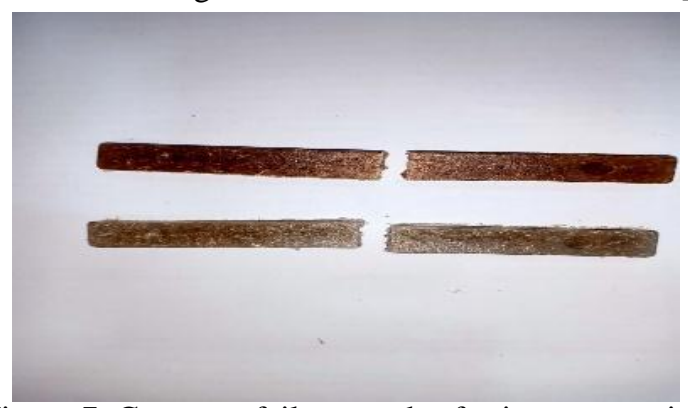

Figure 7. Common failure modes for impact specimen.

Table 4. the Impact strength of SCB fiber-reinforced composites.

\begin{tabular}{|ccc|}
\hline Sample & $\begin{array}{c}\text { Impact energy } \\
\text { (Joule) }\end{array}$ & $\begin{array}{c}\text { Impact strength } \\
\left(\mathrm{KJ} / \mathrm{m}^{2}\right)\end{array}$ \\
\hline Neat LDPE & 2.9 & 64.4 \\
10\%UTSCB & 3.6 & 80 \\
20\%UTSCB & 3.8 & 84.44 \\
30\%UTSCB & 4.2 & 93.33 \\
10\%TSCB & 3.7 & 82.22 \\
20\%TSCB & 4 & 88.89 \\
30\%TSCB & 4.5 & 100 \\
\hline
\end{tabular}

\subsection{Hardness}

Figure 9 reveals the effect of percentage of sugarcane bagasse on a polymer matrix composite's hardness property. At $30 \mathrm{wt} \%$ fibre, LDPE reaches its maximum 
hardness value. A significant improvement in the hardness value of the composites was indicated with increasing fibre content, as shown by the results. The findings were likewise in agreement with what was published in [39]. The material hardness increases by rising its resistance deformation. When more filler is added, the hardness of the materials improves.

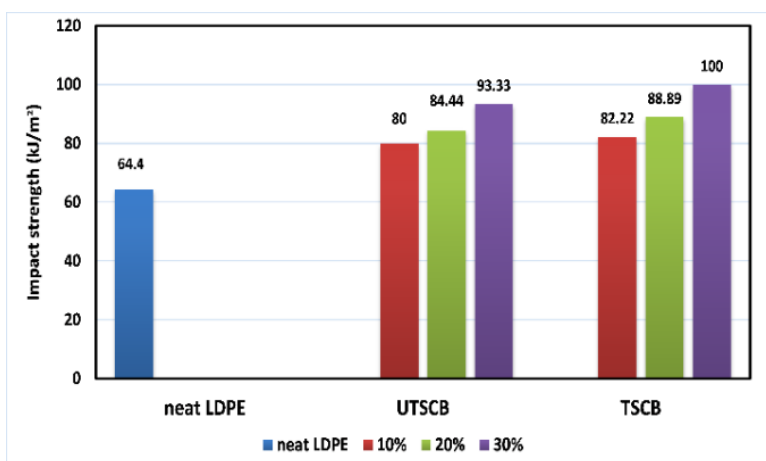

Figure 8. Impact strength of SCB fiber-reinforced composites.

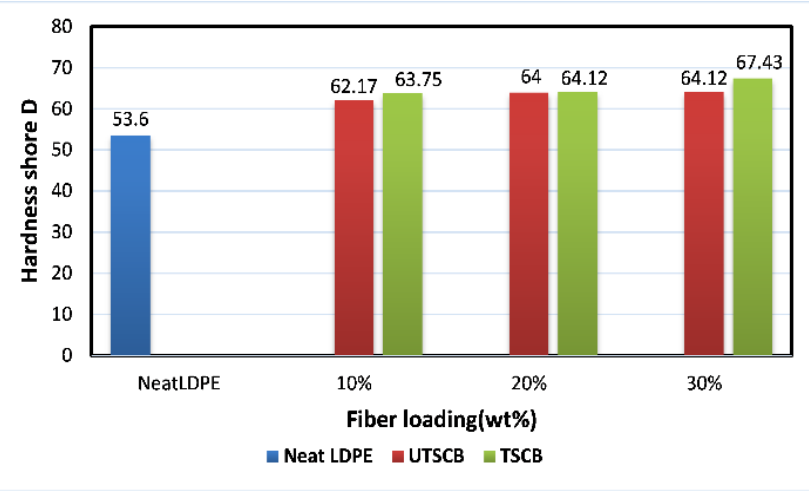

Figure9. Hardness shore D of SCB fiber-reinforced composites.

\subsection{Chemical resistance}

Figure 10 illustrates the percentage absorption of SCB/LDPE composites. In most chemicals, increasing the fiber content increases the percentage absorbance of SCB/LDPE composite. It implies that when fiber content rises, their chemical resistance collapses. Because more fibers are exposed to chemicals, so the chemical resistance decreases[40]. In general, the increase in weight gained occurred due to the hydrophilicity of lingocellulosic fibers for the water or aqueous solutions. It was observed that in all cases the percentage of weight gained was greater in the samples containing treated fibers[41]. In these, the $\mathrm{OH}$ groups in cellulose were more exposed, and this increases the hydrophilicity of the system. From the figures, it is obvious that weight gain is detected for almost all chemical reagents used when the natural fibers of the composite were pretreated with alkali[31]. The percentage of absorption For untreated SCB compostite is lower then treated SB composite because there are awaxy layer prevents chemicals from pentration. Increasing the weight gain of the samples indicates there is good interaction between the fiber and the chemical solutions. Therefore, there is a poor chemical resistance of the substance, so the lower the absorption, the better the resistance. It is the general principle behind the analysis. Amongest all the chemicals, samples have shown maximum absorption for $\mathrm{NaOH}$. In general, the calculation absorption was larger for aqueous solutions, and this was to be expected due to the fiber's hydrophilicity. This conclusion is supported by the weight increase in the presence of these liquids with increasing fiber content. [40]. The percentage of absorption For untreated SCB compostite is lower then treated SCB composite because there are awaxy layer prevent chemicals from pentration.

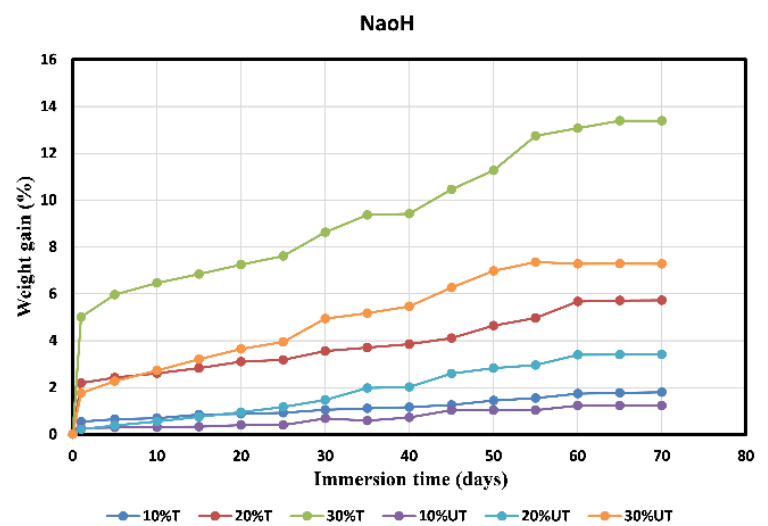

(a)

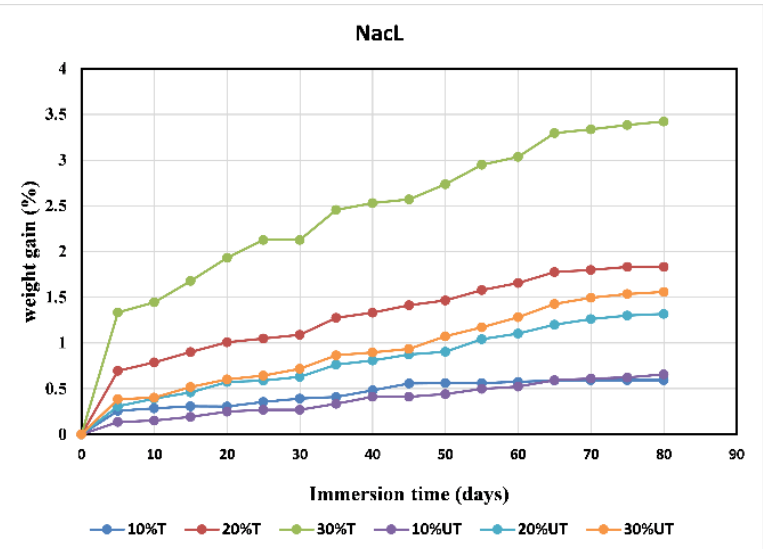

(b) 
H2SO4

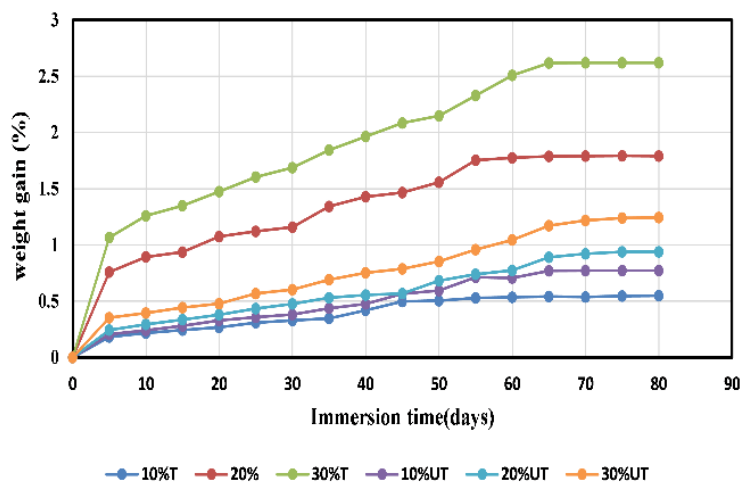

(c)

Figure 10. Chemical resistance of SCB fiber-reinforced composites. a) $\mathrm{NaOH}$ b) $\mathrm{NaCl} \mathrm{C)} \mathrm{H} 2 \mathrm{SO} 4$

\subsection{SEM}

Figure11 shows SEM images of the fractured surface of a treated SCB reinforced LDPE composite with alkali-treated SCB fibers. Fiber distribution and dispersion in the matrix were found to be satisfactory. Additionally, alkali treatment eliminates waxes from the surface of the fiber and creates a strong chemical interaction between the fibres and the matrix. Untreated SCB, however, had significant agglomerates of fibers on the fracture surfaces. The presence of decohesion between the fiber and the matrix confirms this.

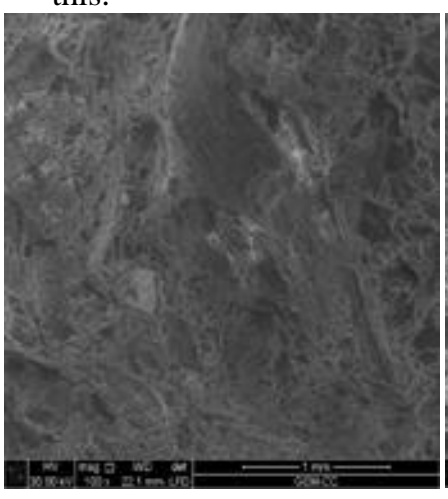

(a)

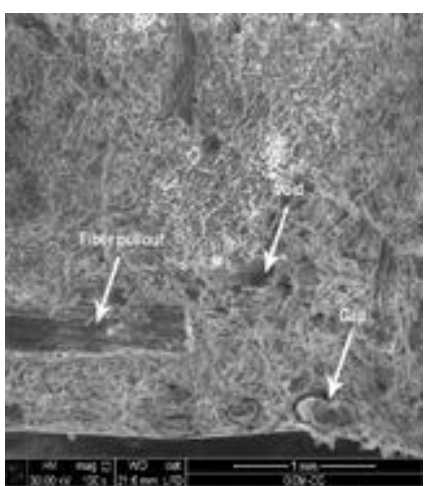

(b)
Figure11 SEM tensile fracture surface of sugarcane bagasse reinforced LDPE (a)treated (b)untreated

\section{CONCLUSIONS}

From this research paper, the investigation of the effect of chemical treatment on the mechanical properties of SCB fibers was achieved and presented. It has been found that:
1. The alkali treatment of SCB significantly improves the tensile strength and modulus of all the fabric-reinforced composites compared to untreated SCB fibers.

2. The alkalization treatment of SCB also improves the impact and hardness properties of the SCB/LDPE composite significantly compared to untreated SCB fibers.

3. Chemical resistance decreased with an increased fiber content from $10 \mathrm{wt} \%$ to $30 \mathrm{wt} \%$ fiber .

4. Composites have shown maximum absorption in $\mathrm{NaOH}$ solution.

\section{Acknowledgments}

The authors would thank Prof. Dr. Mona abo el Wafa Mechanical Design and Production Eng. Department, Faculty of Eng., Zagazig University, Egypt for his support and guidance.

\section{References}

[1] G. R. Arpitha and B. Yogesha, "ScienceDirect An Overview on Mechanical Property Evaluation of Natural Fiber Reinforced Polymers," Mater. Today Proc., vol. 4, no. 2, pp. 2755-2760, 2017, doi: 10.1016/j.matpr.2017.02.153.

[2] I. Oluwole, I. Oghie, A. Damilola, and S. Isaac, "E ff ect of mercerization on the mechanical and thermal response of hybrid bagasse fi ber / $\mathrm{CaCO} 3$ reinforced polypropylene composites," Polym. Test., vol. 76, no. March, pp. 192-198, 2019, doi: 10.1016/j.polymertesting.2019.03.021.

[3] Z.S. El-Kinani, D.Saber, A.M.Hassan "Characterization of Wood Plastic Composites by using Positron Annihilation System" The Egyptian International Journal of Engineering Sciences and Technology, (2018)

[4] N. Patel and P. Jain, "An investigation on mechanical properties in randomly oriented short natural fiber reinforced composites," Mater. Today Proc., no. xxxx, 2020, doi: 10.1016/j.matpr.2020.05.452.

[5] M. J. M. Ridzuan, M. S. A. Majid, M. Afendi, K. Azduwin, and S. N. Aqmariah, "The effects of the alkaline treatment's soaking exposure on the tensile strength of Napier fibre," Procedia Manuf., vol. 2, no. February, pp. 353-358, 2015, doi: 10.1016/j.promfg.2015.07.062.

[6] M. N. Akhtar et al., "Influence of alkaline treatment and fiber loading on the physical and mechanical properties of kenaf/polypropylene composites for variety of applications," Prog. Nat. Sci. Mater. Int., vol. 26, no. 6, pp. 657-664, 2016, doi: 10.1016/j.pnsc.2016.12.004.

[7] V. Vilay and M. Mariatti, "SCIENCE AND Effect of fiber surface treatment and fiber loading on the properties of bagasse fiber - reinforced unsaturated polyester composites," vol. 68, pp. 631-638, 2008, doi: 10.1016/j.compscitech.2007.10.005.

[8] A. G. Adeniyi, D. V. Onifade, J. O. Ighalo, and A. S. Adeoye, "A review of coir fiber reinforced polymer composites," Compos. Part B Eng., vol. 176, no. August, p. 107305, 2019, doi: 10.1016/j.compositesb.2019.107305.

[9] P. Madhu, M. R. Sanjay, M. Jawaid, S. Siengchin, A. Khan, and C. I. Pruncu, "A new study on effect of various chemical treatments on Agave Americana fiber for composite reinforcement: Physico-chemical, thermal, mechanical and morphological properties," Polym. Test., vol. 85, no. January, p. 106437, 2020, doi: 10.1016/j.polymertesting.2020.106437. 
[10] M. Ho et al., "Composites: Part B Critical factors on manufacturing processes of natural fibre composites," Compos. Part B, vol. 43, no. 8, pp. 3549-3562, 2012, doi: 10.1016/j.compositesb.2011.10.001.

[11] M. R. Islam and M. D. H. Beg, "EFFECT OF COUPLING AGENT ON MECHANICAL PROPERTIES OF COMPOSITE FROM KENAF AND RECYCLED POLYPROPYLENE," no. December, pp. 871-875, 2010.

[12] I. Ben Amor, M. Arous, and A. Kallel, "Effect of maleic anhydride on dielectric properties of natural fiber composite," J. Electrostat., vol. 72, no. 2, pp. 156-160, 2014, doi: 10.1016/j.elstat.2013.12.006.

[13] I. O. Oladele, I. O. Ibrahim, A. D. Akinwekomi, and S. I. Talabi, "Effect of mercerization on the mechanical and thermal response of hybrid bagasse fiber/CaCO 3 reinforced polypropylene composites," Polym. Test., vol. 76, no. February, pp. 192-198, 2019, doi: 10.1016/j.polymertesting.2019.03.021.

[14] R. Sepe, F. Bollino, L. Boccarusso, and F. Caputo, "Influence of chemical treatments on mechanical properties of hemp fiber reinforced composites," Compos. Part B Eng., vol. 133, pp. 210-217, 2018, doi: 10.1016/j.compositesb.2017.09.030.

[15] M. R. Sanjay, S. Siengchin, J. Parameswaranpillai, M. Jawaid, C. I. Pruncu, and A. Khan, "A comprehensive review of techniques for natural fibers as reinforcement in composites: Preparation, processing and characterization," Carbohydr. Polym., vol. 207, no. November 2018, pp. 108-121, 2019, doi: 10.1016/j.carbpol.2018.11.083.

[16] E. Farkas and H. Purwaningsih, "Alkali treatment of lignocellulosic fibers extracted from sugarcane bagasse: Composition, structure, properties Andr a cz o Felycia Edi Soetaredjo , J a," Polym. Test., vol. 88, no. January, 2020, doi: 10.1016/j.polymertesting.2020.106549.

[17] S. Radoor, J. Karayil, S. M. Rangappa, S. Siengchin, and J. Parameswaranpillai, "A review on the extraction of pineapple, sisal and abaca fibers and their use as reinforcement in polymer matrix," Express Polym. Lett., vol. 14, no. 4, pp. 309-335, 2020, doi: 10.3144/expresspolymlett.2020.27.

[18] R. Maryana, D. Ma'rifatun, I. A. Wheni, S. K.w., and W. A. Rizal, "Alkaline pretreatment on sugarcane bagasse for bioethanol production," Energy Procedia, vol. 47, pp. 250-254, 2014, doi: 10.1016/j.egypro.2014.01.221.

[19] J. Alexandre, V. Brait, J. Manoel, and L. Henrique, "Effect of Fiber Treatment Condition and Coupling Agent on the Mechanical and Thermal Properties in Highly Filled Composites of Sugarcane Bagasse Fiber / PP," vol. 19, no. 4, pp. 746-751, 2016.

[20] V. Santhanam and M. Chandrasekaran, "Effect of surface treatment on the mechanical properties of banana-glass fibre hybrid composites," Appl. Mech. Mater., vol. 591, pp. 7-10, 2014, doi: 10.4028/www.scientific.net/AMM.591.7.

[21] D. R. Mulinari, J. R. Guedes, and B. G. Simba, "Low density polyethylene composites reinforced with Australian King Palm fibers: mechanical and thermal properties," Polym. Bull., vol. 74, no. 11 , pp. 4549-4559, 2017, doi: 10.1007/s00289-0171963-9.

[22] G. H. Kumar, H. Babuvishwanath, R. Purohit, P. Sahu, and R. S. Rana, "Investigations On Mechanical Properties Of Glass And Sugarcane Fiber Polymer Matrix Composites," Mater. Today Proc., vol. 4, no. 4, pp. 5408-5420, 2017, doi: 10.1016/j.matpr.2017.05.052.

[23] D. Ray, B. K. Sarkar, A. K. Rana, and N. R. Bose, "Effect of alkali treated jute fibres on composite properties," Bull. Mater. Sci., vol. 24, no. 2, pp. 129-135, 2001, doi: 10.1007/BF02710089.

[24] Y. Cao, S. Shibata, and I. Fukumoto, "Mechanical properties of biodegradable composites reinforced with bagasse fibre before and after alkali treatments," vol. 37, pp. 423-429, 2006, doi: 10.1016/j.compositesa.2005.05.045.

[25] M. A. Abd El-Baky, M. Megahed, H. H. El-Saqqa, and A. E. Alshorbagy, "Mechanical Properties Evaluation of Sugarcane Bagasse-Glass/ Polyester Composites," J. Nat. Fibers, vol. 18, no. $8, \quad$ pp. 1163-1180, 2019, doi: 10.1080/15440478.2019.1687069.

[26] D. Mihaela, Z. Vuluga, C. Gabriela, C. Andi, A. Raluca, and R. Trusca, "High flow polypropylene / SEBS composites reinforced with differently treated hemp fibers for injection molded parts," Compos. Part B, vol. 174, no. June, p. 107062, 2019, doi: 10.1016/j.compositesb.2019.107062.

[27] B. L. S. Sipiäo, R. L. M. Paiva, S. A. S. Goulart, and D. R. Mulinari, "Effect of chemical modification on mechanical behaviour of polypropylene reinforced pineapple crown fibers composites," Procedia Eng., vol. 10, pp. 2028-2033, 2011, doi: 10.1016/j.proeng.2011.04.336.

[28] S. Vigneshwaran et al., "Recent advancement in the natural fiber polymer composites: A comprehensive review," J. Clean. Prod., p. 124109, 2020, doi: 10.1016/j.jclepro.2020.124109.

[29] P. Blends, C. Division, and A. Pradesh, "Chemical Resistance and Tensile Polyester Blend Coated," vol. 22, no. 11, pp. 1029-1034, doi: 10.1177/073168403024571.

[30] M. Jawaid, H. P. S. Abdul Khalil, A. Hassan, and E. Abdallah, "Bi-layer hybrid biocomposites: Chemical resistant and physical properties," BioResources, vol. 7, no. 2, pp. 23442355, 2012, doi: 10.15376/biores.7.2.2344-2355.

[31] K. John and S. V. Naidu, "Chemical resistance of sisal/glass reinforced unsaturated polyester hybrid composites," J. Reinf. Plast. Compos., vol. 26, no. 4, pp. 373-376, 2007, doi: $10.1177 / 0731684406072524$.

[32] T. Ganapathy, R. Sathiskumar, P. Senthamaraikannan, S. S. Saravanakumar, and A. Khan, "Characterization of raw and alkali treated new natural cellulosic fibres extracted from the aerial roots of banyan tree," Int. J. Biol. Macromol., vol. 138, pp. 573-581, 2019, doi: 10.1016/j.ijbiomac.2019.07.136.

[33] S. Siddika, F. Mansura, M. Hasan, and A. Hassan, "Effect of reinforcement and chemical treatment of fiber on The Properties of jute-coir fiber reinforced hybrid polypropylene composites," Fibers Polym., vol. 15, no. 5, pp. 1023-1028, 2014, doi: 10.1007/s12221-014-1023-0.

[34] I. Hanafi, "Effects of Polyethylene-g-maleic Anhydride on Properties of Low Density Polyethylene/ Thermoplastic Sago Starch Reinforced Kenaf Fibre Composites," vol. 19, no. 7, pp. 501-510, 2010.

[35] T. P. Mohan and K. Kanny, "Composites: Part A Chemical treatment of sisal fiber using alkali and clay method," Compos. PART A, vol. 43, no. 11, pp. 1989-1998, 2012, doi: 10.1016/j.compositesa.2012.07.012.

[36] Y. Cao, S. Shibata, and I. Fukumoto, "Mechanical properties of biodegradable composites reinforced with bagasse fibre before and after alkali treatments," Compos. Part A Appl. Sci. Manuf., vol. 37, no. 3, pp. 423-429, 2006, doi: 10.1016/j.compositesa.2005.05.045.

[37] R. S. N. Sahai and R. A. Pardeshi, "Comparative study of effect of different coupling agent on mechanical properties and water absorption on wheat straw-reinforced polystyrene composites," J. Thermoplast. Compos. Mater., vol. 34, no. 4, pp. 433-450, 2021, doi: 10.1177/0892705719843975.

[38] S. Madhavi, N. V. Raju, and J. Johns, "Characterization of Bamboo - Polypropylene Composites: Effect of Coupling Agent," Fibers Polym., vol. 0, no. 0, pp. 1-9, 2021, doi: 10.1007/s12221-021-0027-9.

[39] G. Saini, A. K. Narula, V. Choudhary, and R. Bhardwaj, "Effect of particle size and alkali treatment of sugarcane bagasse on thermal, mechanical, and morphological properties of pvc-bagasse composites," J. Reinf. Plast. Compos., vol. 29, no. 5, pp. 731-740, 2010, doi: 10.1177/0731684408100693. 
[40] A. Gupta, "Synthesis, Chemical Resistance, and Water Absorption of Bamboo Fiber Reinforced Epoxy Composites Anu," Polym. Compos., vol. 16, no. 2, pp. 101-113, 2016, doi: $10.1002 / \mathrm{pc}$.

[41] P. Noorunnisa Khanam, H. P. S. Abdul Khalil, G. Ramachandra Reddy, and S. Venkata Naidu, "Tensile, Flexural and Chemical Resistance Properties of Sisal Fibre Reinforced Polymer Composites: Effect of Fibre Surface Treatment," J. Polym. Environ., vol. 19, no. 1, pp. 115-119, 2011, doi: 10.1007/s10924-010-0219-7. 